observations in other places in the province. This phenomenon is quite prevalent south of Moose Jaw and also at Bateman. In these other places, though, the operation did not seem nearly as well organized. There were no trails leading from the nest to the bushes and there were fewer aphids in proportion to the ants. In these cases it is quite likely that the aphids serve only as a secondary source of food for the ants.

I also noticed aphids on the hoary sage-bush only when there were ants living in symbiosis with them. I was able to deduce from this that the aphids are kept over winter by the ants in their ant hills and that in the spring when the sap starts to flow, the ants place them on the bushes. This phenomenon shows that ants have an ability almost equal to that of human beings for utilizing their environment to produce food. It is known. too, that many ants keep gardens of fungus growing in their nests as a dependable source of food, and that other ants raise slaves to help them secure food. It is interesting to think that the rather complex form of the ant community has been in existence for many years-indeed students of paleontology have fairly well established that ants and aphids lived in harmony sixty million years ago.

\title{
MAMMALOGIST APPOINTED TO THE STAFF OF THE UNIVERSITY OF SASKATCHEWAN
}

Members of the Saskatchewan Natural History Scciety who attended the annual meeting in Saskatoon had the pleasure of hearing a talk on animal populations by Dr. R. S. Miller, newly appointed Assistant Professor of Biology at the University of Saskatchewan. We hope that we may see him at many of our meetings and that we shall cften see his name in the Blue Jay.

Dr. Miller was born in Cleveland, Ohio, and spent five years in the U. S. Air Force before attending university. He obtained his B.A. from the University of Colorado in 1949 and his Ph.D. from Oxford in 1951.

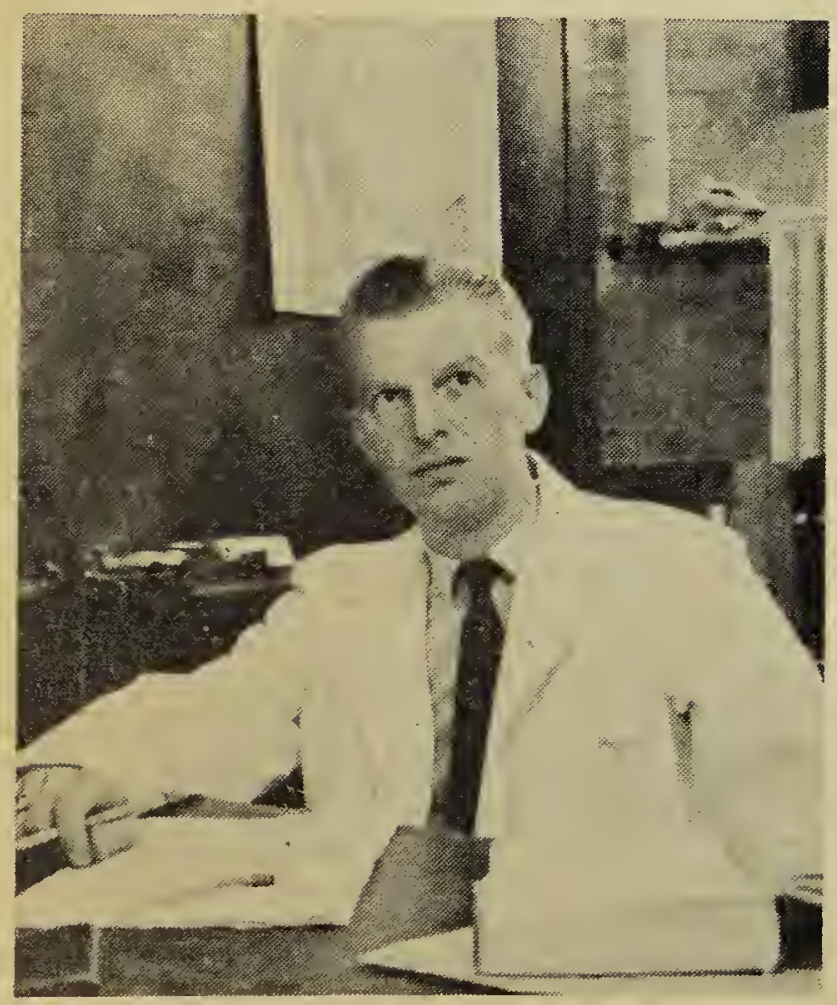

Richard' S. Miller
From 1952 to 1955, he instructed at Harvard in elementary zoology, general ecology and population ecology. From 1955 to 1958, he was associate biologist at Colorado State University doing research on small mammal populations, primarily on pocket gophers (Geomyidae).

Dr. Miller has published research papers on the activity rhythms, food habits, population changes a n d movements of the Field Mouse (Apodemus sylvaticus) and of the Bank Vole (Clethrionomys glareolus); he has also studied the rate of growth of incisors of pocket gcphers and the effect of crowding on longevity of adult Drosophila melanogaster. He continues to be interested in population studies of small mammals with special emphasis on the theory of competition in population ecology. Dr. Miller has completed research which he hopes to publish soon on the competition between two closely related species of Drosophila and on the ecology and distribution of pocket gophers of Colorado.

In his speech at the annual meeting Dr. Miller made a strong plea for complete and careful scientific study of all the possible effects of any human attempt to control or limit the population of any animal. People who are interested in mammals will be glad to know that there is a mammalogist in the Biology Department of the University to give help and guidance to the amateur. 